\title{
Evapotranspiração máxima do tomateiro sob estufa plástica em função de variáveis fenométricas e meteorológicas
}

\author{
Carina Rejane Pivetta ( $\left(^{*}\right)$; Arno Bernardo Heldwein ('); Ivonete Fátima Tazzo ('); \\ Ivan Carlos Maldaner ('); Leandro Dalbianco ('); Nereu Augusto Streck ('); \\ Rui Manuel Almeida Machado $\left.{ }^{2}\right)$

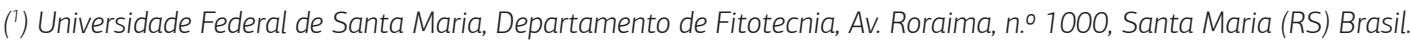 \\ (2) Universidade de Évora, Instituto de Ciências Agrárias e Ambientais Mediterrânicas, Apartado 94, 7002-554 Évora, Portugal. \\ (*) Autora correspondente: carina.pivetta@gmail.com
}

Recebido: 1.\%ago./2010; Aceito: 2/mar./2011

\begin{abstract}
Resumo
O objetivo do trabalho foi estimar a evapotranspiração máxima (ETm) da cultura do tomateiro em estufa plástica em função da evaporação medida no evaporímetro de Piche exposto à radiação solar (Epi), com e sem a inclusão de outras variáveis meteorológicas e fenométricas pontuais de fácil mensuração, na época de primavera de 2005. Em uma estufa plástica realizaram-se medidas de ETm em lisímetros de drenagem (Epi) temperatura e déficit de pressão de vapor no ar (D), índice de área foliar (IAF), altura de plantas (AP) e número de folhas (NF). Ajustaram-se modelos para estimar a ETm com os dados dos dias pares do período de medições, selecionando-se os que tinham parâmetros angulares significativos pelo teste t a 5\% de probabilidade de erro e coeficiente de determinação $\left(R^{2}\right)$ maior que 0,85 . Os modelos foram testados com os dados dos dias ímpares da série de dados do mesmo período, por meio da análise de regressão entre os valores observados e estimados pelos modelos, considerando-se a raiz quadrada do quadrado médio do erro (RMSE) e os índices de precisão (r), concordância (d) e confiança (c). Verificou-se que é possível estimar a ETm do tomateiro com precisão aceitável ( $R^{2}$ entre 0,87 e 0,92), para fins de irrigação sob estufa, através de modelos que incluem valores de Epi e pelo menos uma variável fenométrica, dando-se preferência aos modelos que incluem a variável AP, por ser a variável de mais fácil mensuração. $A$ inclusão de $D$ medido às 9 horas nos modelos que incluem Epi e AP ou NF ou IAF, melhora a estimativa da ETm.
\end{abstract}

Palavras-chave: irrigação, evaporímetro de Piche, Lycopersicon esculentum Mill., cultivo protegido.

\section{Maximum evapotranspiration of tomato grown under plastic greenhouse based upon meteorological and phenological variables}

\begin{abstract}
The objective of this study was to estimate the maximum evapotranspiration (ETm) of tomato inside greenhouse as a function of evaporation measured with "Piche" evaporimeter exposed to solar radiation (Epi) with and without easily measured meteorological and phenological variables during the 2005 spring growing season. Daily ETm (measured with drainage lysimeters), Epi, air temperature, air vapor pressure deficit (D), leaf area index (LAl), plant height (PH), and number of leaves (LN) were measured. Models were fitted to estimate ETm using data collected on even days of the experimental period. In the multiple regression analysis only models with parameters significant at $5 \%$ by t test and coefficient of determination $\left(R^{2}\right)$ greater than 0.85 were selected. Models were evaluated with independent data collected on odd days of the period. Statistics used for model evaluation were regression analyses between observed and estimated data, root mean square error (RMSE), and accuracy (r), agreement (d) and confidence (c) indices. Results showed that it is possible to estimate ETm of tomato crop with acceptable accuracy ( $R^{2}$ between 0.87 e 0.92 ) to perform irrigation inside plastic greenhouse using models that take into account Epi and at least one plant growth parameter; models with PH should be preferred. Including D measured at $9 \mathrm{~h}$ in the models with Epi and LN or PH or LAl improved ETm estimates.
\end{abstract}

Key words: irrigation, Piche evaporimeter, Lycopersicon esculentum Mill., greenhouse crops. 


\section{INTRODUÇÃO}

O cultivo em estufas plásticas é uma técnica consolidada e importante na agricultura de pequena escala e cada vez mais se expande mundialmente. A proteção física dos cultivos é a principal alternativa para produzir hortaliças fora da época de safra, reduzindo a sazonalidade e os efeitos negativos de adversidades climáticas na produção (Manrique, 1993). É o caso da região fisiográfica da Depressão Central do Rio Grande do Sul que, em condiçóes subtropicais úmidas, dificulta o cultivo na época mais fria do ano.

As vantagens atribuídas às estufas se devem ao efeito da barreira física imposta pela cobertura plástica, ao tipo de material que a constitui e ao manejo de abertura e fechamento, responsáveis pelas parciais alteraçóes meteorológicas nesses ambientes. A radiaçáo solar, a velocidade do vento, a temperatura e a umidade relativa do ar são os elementos mais afetados e determinantes da demanda hídrica atmosférica. Ortega-Farías et al. (2004) mencionam que o saldo de radiação solar disponível é a principal energia determinante das perdas de água por um dossel de plantas quando a água no solo não é limitante. ZHANG et al. (2010) também reforçam a variação que ocorre na evapotranspiração em ambiente protegido em função dos parâmetros ambientais, principalmente a radiação solar, a temperatura do ar e o déficit de pressão de vapor no ar.

O grau de variação entre estes resulta na formação de um microclima, de maneira que o desenvolvimento e o manejo do dossel vegetativo tornam-se diferenciados do que ocorre no exterior destes ambientes (Orgaz et al., 2005). Consequentemente, os parâmetros determinados para as mesmas espécies em ambientes expostos às condiçóes meteorológicas naturais, passam a não ser adequados aos cultivos protegidos, principalmente quanto ao suprimento hídrico, alterado em função da significativa redução na demanda hídrica atmosférica, que determina uma redução na evapotranspiraçáo (FARIAS et al., 1994; Martins, et al., 1999; Rezende et al., 2004).

Neste contexto, a irrigaçáo é o manejo mais afetado, ou seja, a maneira e a quantidade de água fornecida às plantas devem ser ajustadas para que não haja condiçóes de estresse por excesso ou deficiência hídrica, o que levaria ao comprometimento do crescimento e desenvolvimento das plantas. O pré-requisito para a eficiência da irrigação é a quantificação do consumo de água e a evapotranspiração máxima das culturas (ETm) (Orgaz et al., 2005). No entanto, faltam técnicas de fácil determinação da ETm sob estufa plástica, principalmente daquelas de fácil utilização por produtores menos instruídos, como, por exemplo, tabelas geradas por modelos que estimem a ETm com base em variáveis meteorológicas e fenométricas de simples medição. Geralmente, o que se encontra na bibliografia são modelos que incluem variáveis como a radiação solar e o déficit de pressão de vapor no ar. Porém, ao nível de agricultores, o seu uso é pouco viável devido ao custo dos equipamentos e à necessidade de máo de obra treinada.

Uma alternativa que vem sendo estudada é o uso do evaporímetro de Piche, que é um instrumento muito simples, de baixo custo e fácil manejo para a medida da evaporação (Papaionnnou et al., 1998). Domuta et al. (2007) utilizaram o evaporimetro de Piche para quantificar a irrigação do tomateiro cultivado sob solário e verificaram ser eficiente para o manejo da irrigação nessas condiçōes. Em trabalho com pimentão cultivado em estufa plástica, a ETm foi satisfatoriamente estimada em função da evaporação medida no evaporímetro de Piche (Epi) exposto ao sol nas mesmas condiçóes que a parte superior das plantas (Heldwein et al., 2001). Porém, trabalhos referentes à estimativa de ETm em função de Epi carecem de uma ampla difusão, tendo em vista que esses equipamentos medem com bastante precisão a demanda hídrica atmosférica, viabilizando a estimativa da ETm pelos modelos matemáticos ou tabelas e que poderiam ser facilmente utilizados nos cultivos em estufas plásticas.

O objetivo deste trabalho foi estimar a evapotranspiração máxima da cultura do tomateiro cultivado em estufa plástica, em função da evaporação medida no evaporímetro de Piche exposto à radiação solar, com e sem a inclusão de outras variáveis meteorológicas e fenométricas.

\section{MATERIAL E MÉTODOS}

O experimento foi realizado na primavera de 2005 em estufa plástica $\left(240 \mathrm{~m}^{2}\right)$, com cobertura em forma de arco e coberta com filme de polietileno de baixa densidade (PEBD) com $150 \mu \mathrm{m}$ de espessura, orientada no sentido Norte-Sul. A ventilação da estufa foi realizada, quando necessário, por meio da abertura e fechamento das cortinas laterais e das portas frontais. A estufa localiza-se a $29^{\circ}$ $42^{\prime} \mathrm{S}, 53^{\circ} 48^{\prime} \mathrm{O}$ e $95 \mathrm{~m}$ de altitude.

O clima da região é do tipo Cfa, subtropical úmido com veróes quentes, conforme a classificação de Köppen, com temperaturas médias normais do ar variando de $12,9{ }^{\circ} \mathrm{C}$ no mês de junho a $24,6{ }^{\circ} \mathrm{C}$ no mês de janeiro (Moreno, 1961). A disponibilidade de radiação solar geralmente é superior a $16,7 \mathrm{MJ} \mathrm{m}^{-2} \mathrm{dia}^{-1}$ nos meses de verão (Buriol et al., 1991), e inferior a $8,4 \mathrm{MJ} \mathrm{m}^{-2} \mathrm{dia}^{-1}$ nos meses de junho e julho (Estefanel et al., 1998). O solo é classificado como Argissolo Vermelho Distrófico arênico (Embrapa, 2006) e pertence à Unidade de Mapeamento São Pedro (Brasil, 1973).

A adubação química do solo foi realizada seguindo as recomendaçōes oficiais da Comissão de Fertilidade do Solo do Rio Grande do Sul e Santa Catarina (2004), com base nos resultados da análise do solo. A incorporação do adubo foi efetuada com ajuda de uma enxada somente nas fileiras de plantio. Em cada fileira foi construído um camalhão com cerca de $0,10 \mathrm{~m}$ de altura e $0,30 \mathrm{~m}$ de largura. 
Para a irrigação das fileiras, consideradas como bordadura, foram utilizados gotejadores autocompensados com vazáo de $1,65 \mathrm{~L} \mathrm{~h}^{-1}$, espaçados a cada $0,30 \mathrm{~m}$, com pressão máxima de trabalho de $1000 \mathrm{hPa}$. Os tubos gotejadores foram instalados em um pequeno sulco que percorria toda a extensão central de cada camalhão. Os camalhóes foram individualmente recobertos com PEBD opaco, de cor preta, com $30 \mu \mathrm{m}$ de espessura (mulching), esticado e fixado com o próprio solo nas extremidades e nas bases laterais do camalhão. $\mathrm{O}$ mulching foi utilizado para auxiliar no controle de plantas invasoras e na redução da evaporação de água na superfície do solo. O transplante das mudas do tomateiro híbrido 'Max' com raiz protegida foi aos 45 dias após a semeadura, com espaçamento de 1,0 m entre linhas e 0,30 m entre as plantas.

A água a ser irrigada foi medida por hidrômetros tipo unijato, de baixa vazão, mediante controle por registros de pressão. A irrigaçáo das fileiras foi efetuada diariamente em função do potencial matricial da água no solo, medido em quatro tensiômetros de cápsula porosa e manômetro de mercúrio, instalados dois no lado leste e dois no oeste da estufa nas profundidades de 0,10 e 0,20 m. As leituras diárias das colunas de mercúrio foram realizadas no turno da manhã, cerca de 30 minutos após o nascer do sol e a tomada de decisão para a irrigação foi baseada na demanda evaporativa da atmosfera e quando a coluna de mercúrio atingia valores maiores ou iguais a $17,33 \mathrm{kPa}$.

A medida da ETm foi realizada pelo método da lisimetria e consistiu da construção de três repetiçóes de lisímetros de drenagem com substrato (Figura 1). Os lisímetros foram construídos com calhas de PVC com
0,20 m de diâmetro e $1,5 \mathrm{~m}$ de comprimento, revestidas e impermeabilizadas com PEBD opaco, de cor preta, assim como nas fileiras de plantas no solo, ou seja, constituindo-se no mulching para evitar a perda da água drenada após as irrigaçóes e a evaporação na superfície do substrato. A calha foi colocada sobre os camalhóes (intervalo deixado sem plantas) com um pequeno desnível para facilitar o escoamento da água drenada. Em uma das extremidades da calha, o plástico foi unido formando um canal em forma de funil, conduzindo a soluçáo drenada para o interior de um reservatório de coleta. Em cada calha foram acondicionadas cinco plantas, cultivadas em sacolas plásticas independentes, perfuradas e preenchidas com oito litros de substrato agrícola esterilizado, conforme descrito por VALANDro et al. (1999) e com o mesmo espaçamento utilizado para as plantas cultivadas na bordadura. $\mathrm{O}$ reservatório de água $(32 \mathrm{~L})$ destinado à irrigação foi instalado na parte central da estufa, com sua base a cerca de 1,0 m acima do nível do solo. Na parte externa do reservatório foi colada uma régua com escala em milímetros para medir o volume de água irrigada pela diferença de nível, observado através de um tubo de plástico transparente de pequeno diâmetro, colado paralelo à régua e conectado ao reservatório pela sua base. $\mathrm{O}$ sistema de irrigaçáo foi individualizado para cada uma das cinco plantas nas sacolas por meio de tubos flexíveis de pequeno diâmetro $(0,002 \mathrm{~m})$, chamados "espaguete"; o volume de água aplicado foi controlado por um registro de pressão instalado junto ao lisímetro, conectado ao reservatório por um tubo flexível de distribuição da água. Em cada calha, o excesso de água escoado após cada irrigação foi

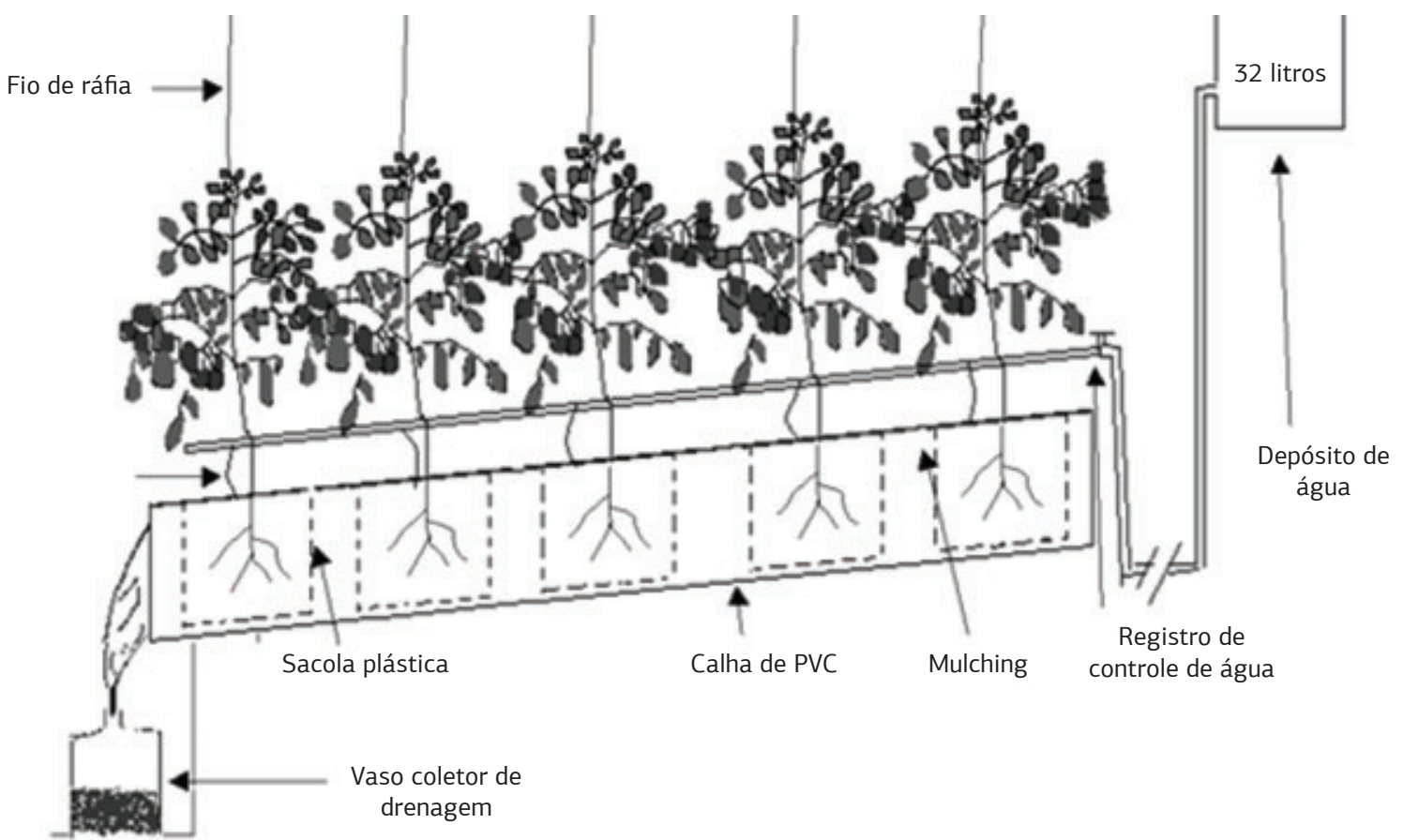

Figura 1. Esquematização do lisímetro de drenagem com substrato utilizado no experimento. 
contabilizado como água drenada e quantificado com o auxílio de provetas.

A ETm em cada lisímetro foi calculada pela diferença entre a água irrigada e a drenada no período subsequente. Essa diferença representou a água a ser reposta na irrigação posterior. Foram realizadas três irrigaçóes diárias (às $07 \mathrm{~h} 30 \mathrm{~min}, 12 \mathrm{~h} 30 \mathrm{~min}$ e $16 \mathrm{~h}$ ) nas plantas dos lisímetros e semanalmente foi aplicada uma fertirrigação com base na condutividade elétrica da soluçáo drenada em cada lisímetro.

A condução das plantas foi realizada com fitas plásticas (ráfia) enroladas helicoidalmente na vertical da haste principal de cada planta, sustentadas na parte superior por arames lisos de aço número 14, esticados e fixados na altura do pé-direito da estufa. Os tratos culturais como desbrotas, podas, desfolhas e o controle de pragas e doenças foram feitos de acordo com a necessidade da cultura ao longo do ciclo.

As medições fenométricas foram realizadas semanalmente para determinar o índice de área foliar (IAF), a altura das plantas (AP) e o número de folhas (NF) por planta. Para determinar a área foliar (AF) foram realizadas medidas lineares de comprimento (C) e largura (L) de todas as folhas de duas plantas marcadas aleatoriamente em cada lisímetro. A AF de cada planta foi obtida pela soma da área foliar de cada folha calculada pela equação 1. Esta equação foi gerada por regressão entre os valores resultantes da soma do produto entre comprimento e largura das folhas da planta e a respectiva área foliar obtida pelo método destrutivo dos discos foliares. A equação foi selecionada pelo maior coeficiente de determinação $\left(\mathrm{R}^{2}\right)$.

$\mathrm{AF}=0,3676^{*} \mathrm{C}^{*} \mathrm{~L}$

A partir dos dados de AF, determinou-se o IAF para cada planta, obtido pelo quociente entre a AF da planta e a área de solo ocupada por ela. As determinaçôes fenológicas constaram da data de transplante $(\mathrm{T})$, início da floração (IF) (primeira flor aberta), início da maturação dos frutos (IM) (considerando o primeiro fruto maduro) e o fim da colheita (C).

A evaporação de água no interior da estufa foi medida no evaporímetro de Piche (Epi), calculada por diferença do nível de água no tubo graduado em milímetros entre dias subsequentes. Foram instalados quatro evaporímetros, todos expostos à radiaçáo solar, instalados e pendurados por um arame de maneira que nunca estivessem em contato com o topo das plantas, mas sujeitos ao balanço pela movimentação do ar. Assim, os evaporímetros foram içados conforme as plantas cresciam, e atingiram a altura máxima de $2 \mathrm{~m}$ precisando ser suspensos por roldanas. Os evaporímetros foram instalados no vão das janelas laterais, abrangendo o quadrante central da estufa. O papel de filtro da área evaporante do evaporímetro foi trocado quando estava com sujidades, o que ocorreu a cada 5 dias. $\mathrm{O}$ reabastecimento dos evaporímetros foi realizado antes que o nível da água atingisse $2 \mathrm{~mm}$.
A temperatura e a umidade relativa do ar foram monitoradas por dois pares psicrométricos, cada um constituído por dois termômetros (um seco e outro úmido) de resistência elétrica de platina (Pt-100), instalados a 1,5 $\mathrm{m}$ do solo no interior de um miniabrigo com ventilação natural. Estes equipamentos foram conectados a um $d a-$ talogger com registro dos dados a cada dez minutos. Semanalmente, os dados eram retirados para processamento, obtendo-se os valores diários da temperatura mínima $\left(\mathrm{T}_{\text {min }}\right)$ e temperatura das $15 \mathrm{~h}\left(\mathrm{~T}_{15}\right)$. A partir dos dados psicrométricos, foram calculados os valores do déficit de pressáo de vapor no ar das $9 \mathrm{~h}\left(\mathrm{D}_{9}\right)$ e das $15 \mathrm{~h}\left(\mathrm{D}_{15}\right)$.

Os valores de ETm dos dias pares da série de dados foram correlacionados com as correspondentes variáveis meteorológicas e fenométricas através dos modelos de regressão múltipla, efetuando-se as várias combinaçôes entre essas variáveis, escolhidas por acaso, porém sempre mantendo a inclusão da Epi e de pelo menos uma variável fenométrica (IAF, AP ou NF) em todos os modelos. A primeira seleção dos modelos de regressão foi realizada com base nos respectivos coeficientes de determinação $\left(\mathrm{R}^{2}\right)$, os quais deveriam apresentar parâmetros angulares significativos pelo teste t a $5 \%$ de probabilidade e $\mathrm{R}^{2}$ maior que 0,80 .

O programa de linguagem SAS (Statistical Analysis System) (SAs Institute, 1997) foi usado para gerar os modelos matemáticos para estimativa de ETm, bem como para proceder as análises estatísticas dos testes dos modelos.

O teste dos modelos selecionados para a estimativa de ETm constou da análise de regressão simples entre os valores de ETm medidos nos dias pares e os valores de ETm estimados pelos modelos para os dias ímpares do mesmo cultivo do tomateiro na primavera de 2005 . No teste, a seleçâo dos modelos foi baseada considerando-se: os desvios dos parâmetros linear (a) e angular (b) em relaçáo aos da reta 1:1; a raiz do quadrado médio do erro (RMSE); o coeficiente de correlação $(\mathrm{r})$, também denominado de índice de precisão (Camargo e Sentelhas, 1997); o índice de concordância (d), conforme Willmott (1985); e o índice de confiança (c), conforme Camargo e Sentelhas (1997), selecionando-se predominantemente os modelos com desempenho classificado como "ótimo" (O) (Tabela 1).

\section{RESULTADOS E DISCUSSÃO}

A evapotranspiração máxima (ETm) durante o ciclo da cultura totalizou $254,7 \mathrm{~mm}$, dos quais, 20,5, 126,4 e $107,8 \mathrm{~mm}$ ocorreram respectivamente nos subperíodos T-IF (duração de 36 dias), IF-IM (55 dias) e IM-C (26 dias). Os menores valores de ETm diária ocorreram no subperíodo T-IF, o que está relacionado com o reduzido crescimento vegetativo das plantas, medido pelo IAF e AP (Figura 2) e menor demanda hídrica atmosférica em relação aos demais subperíodos. A ETm diária mostrou tendência para um aumento progressivo até os 102 DAT, 
devido aos valores máximos de IAF e do acréscimo natural da disponibilidade de energia proveniente do saldo de radiação, resultante da proximidade do verão. CASANOva et al. (2009) também mencionam a grande influência que a radiação solar exerce na evapotranspiração dos cultivos em ambiente protegido.

No fim do ciclo, que se estendeu até os 122 DAT, houve uma ligeira redução dos valores diários de ETm e de IAF, embora AP e NF tenham mantido a tendência de crescimento. $\mathrm{O}$ aumento de $\mathrm{AP}$ e de NF pode náo ter sido totalmente convertido em área transpirante pelas plantas, uma vez que em NF pode ocorrer a inclusão de folhas senescentes e com tamanho em torno de $1,0 \mathrm{~cm}$, as quais não contribuíram significativamente com a transpiração (Figura 2).

O IAF é uma das variáveis biofísicas mais comumente utilizadas para monitorar o crescimento das culturas agrícolas (Xavier e Vettorazzi, 2003; GonZalez-Sanpedro et al., 2008) pelo qual o estudo da sua relação com ETm assume extrema importância. ETm aumentou com IAF (Figura 3a) e a equaçáo de ajuste apresentou $\mathrm{R}^{2}$ em torno de 0,80 . Contudo, para valores de IAF superiores a 1,0, os desvios em relação à curva de ajuste são maiores, provavelmente relacionados com a variação temporal diária dos elementos meteorológicos, como a radiação solar, temperatura, umidade relativa e déficit de pressão de vapor no ar - condiçóes ambientais que atuam diretamente nos mecanismos de condutância estomática e, consequentemente, na magnitude do processo de transpiração (ELINgs e Voogt, 2008). Salienta-se que, na escala diária, o aumento da área foliar é relativamente pequeno, e assim, as variáveis meteorológicas assumem maior importância na definição da ETm e comandam o transporte de água no sistema solo-planta-atmosfera (DALMAGO et al., 2006).

A Epi ao longo do ciclo do tomateiro totalizou 291,3 $\mathrm{mm}$, ou seja, foi $36,6 \mathrm{~mm}$ mais elevada do que a ETm. Excetuando-se o período inicial, até os 44 DAT, os valores de Epi foram próximos aos de ETm, com a mesma tendência (Figura 2). Nos primeiros 44 DAT, a Epi diária atingiu um valor máximo de 4,75 $\mathrm{mm}$ aos $42 \mathrm{DAT}$, enquanto o valor máximo de ETm foi de 2,48 $\mathrm{mm}$ aos 38 DAT. Estando as plantas e o evaporímetro de Piche expostos às mesmas condiçôes de demanda hídrica atmosférica no interior da estufa, a menor ETm nessa fase do ciclo pode ser explicada principalmente pela reduzida área foliar que as plantas ainda apresentavam, limitando a perda de água por transpiração, somada à redução da evaporaçấo na superfície do substrato pelo efeito da cobertura com o mulching. Em contrapartida, na Epi, em função do evaporímetro de Piche estar instalado fora do abrigo meteorológico e a $1,5 \mathrm{~m}$ acima da superfície do solo, ocorreu evaporação contínua e sem a possível limitação ecofisiológica observada nas plantas, aumentando a evaporação, favorecida pela maior circulação do ar dentro da estufa.
Tabela 1. Intervalos de valores do índice de confiança " $c$ " utilizados para a interpretaçáo do desempenho dos modelos de estimativa da evapotranspiração máxima do tomateiro

\begin{tabular}{lc} 
Valor de "c" & Desempenho \\
$>0,85$ & Ótimo (O) \\
0,76 a 0,85 & Muito bom (MB) \\
0,66 a 0,75 & Bom (B) \\
0,61 a 0,65 & Mediano (MD) \\
0,51 a 0,60 & Sofrível (S) \\
0,41 a 0,50 & Mau (M) \\
$<0,40$ & Péssimo (P) \\
\hline
\end{tabular}

Fonte: Camargo e Sentelhas (1997).

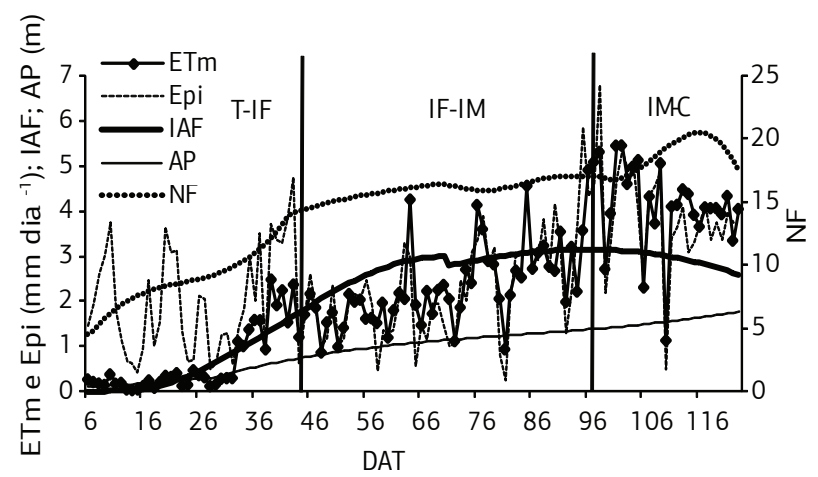

Figura 2. Evapotranspiração máxima (ETm), índice de área foliar (IAF), altura de plantas (AP) e número de folhas (NF) do tomateiro e evaporação medida no evaporímetro de Piche (Epi), em função dos dias após o transplante (DAT), em estufa plástica na primavera de 2005, em Santa Maria (RS). T-IF: subperíodo transplanteinício da floração; IF-IM: subperíodo início da floração-início da maturação de frutos; e IM-C: subperíodo início da maturação de frutos-colheita.

Quando se estabelece a relação de ETm com o IAF (Figura 3a) evidencia-se mais claramente a influência que esta variável tem sobre a ETm. No entanto, ao relacionar ETm ou ETm/Epi com o NF ou AP não ocorre melhoria no ajuste. A explicação para esse fato pode ser a ocorrência de alguns valores muito baixos de Epi que fizeram com que a demanda hídrica atmosférica fosse subestimada nesses dias e por ser o IAF uma medida mais representativa da área transpirante da planta esta variável foi a que melhor se ajustou a essas condiçôes.

$\mathrm{Na}$ figura $3 \mathrm{~b}$ complementa-se a influência de IAF na relação entre ETm e Epi, verificando-se no período em que ocorreu $\mathrm{IAF}<2,0$ nas plantas, ou seja, até os $46 \mathrm{DAT}$, a relação entre ETm e Epi não foi satisfatória $\left(\mathrm{R}^{2}=0,30\right)$. Neste caso, ETm estaria sendo superestimada, caso fosse estimada somente com base nos valores de Epi. Testandose as possibilidades de assumir valores iniciais maiores ou iguais a 1,7 para IAF, encontra-se $\mathrm{R}^{2}=0,75$, e a partir de IAF maior ou igual a 1,5 piora ainda mais a relação 

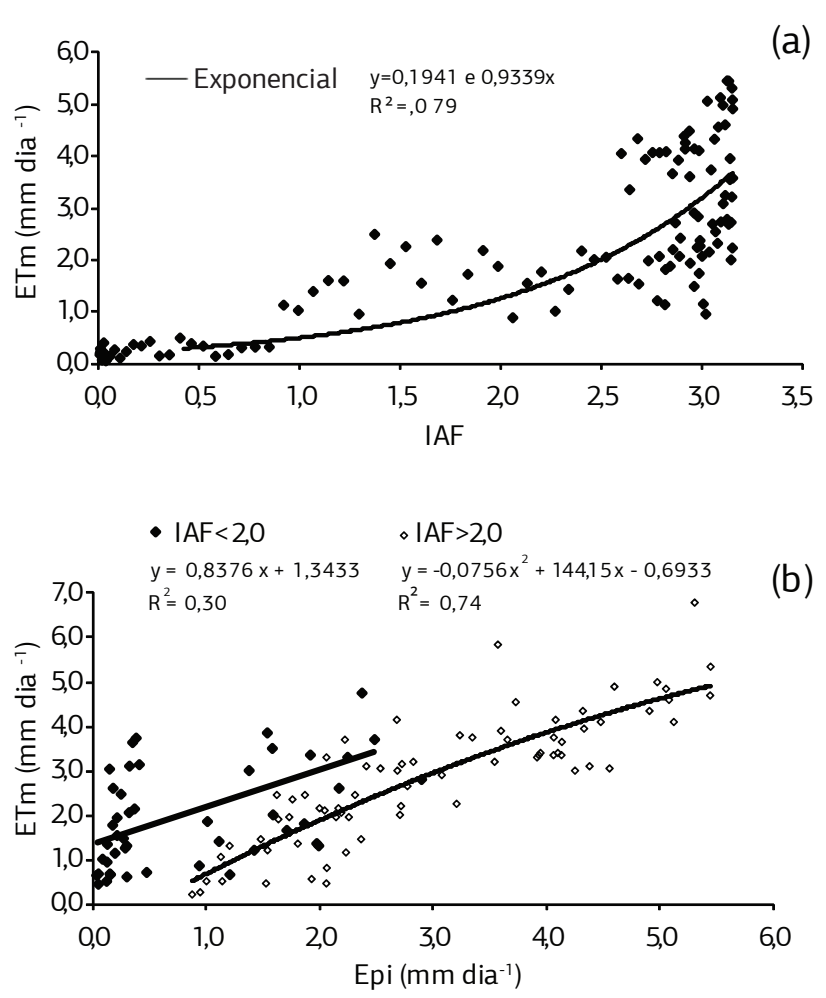

Figura 3. Evapotranspiração máxima do tomateiro (ETm) em funçáo do índice de área foliar (IAF) durante todo o ciclo (a) e ETm em função da evaporação medida no evaporímetro de Piche (Epi) para dois intervalos de IAF (b), em estufa plástica na primavera de 2005, em Santa Maria (RS).

$\left(R^{2}=0,68\right)$, demonstrando que o limite para separar o ciclo do tomateiro em duas fases de influência ou da demanda hídrica atmosférica ou da planta situa-se em torno de um IAF igual a 2,0.

Após os 46 DAT, quando IAF atingiu valores superiores a 2,0, a relação foi melhor $\left(\mathrm{R}^{2}=0,74\right)$ (Figura $3 \mathrm{~b}$ ). Neste período, as condiçóes ambientais, como a maior densidade do fluxo de radiação solar e déficit de pressão de vapor no ar, permitiram o maior tempo diário de abertura da estufa e favoreceram a elevação da demanda hídrica atmosférica e, consequentemente, a maior evaporação no Piche e transpiraçáo das plantas. Corroborando com a situação de similaridade entre os valores de ETm e Epi neste período pode estar associado o fato de que com o IAF superior a 2,0 a área transpirante das plantas, atingiu a magnitude da evaporação no Piche.

Dos modelos de regressão linear obtidos para a estimativa de ETm do tomateiro com a inclusão de Epi, de variáveis fenométricas e meteorológicas pontuais, verifica-se na tabela 2 os que tiveram um coeficiente de determinação $\left(\mathrm{R}^{2}\right)$ maior que 0,80 . Esses modelos da tabela 2 foram os que proporcionaram os melhores resultados e, portanto, os recomendados, pois foram testadas inúmeras relaçóes para a determinação da ETm, inclusive transformando-se ETm/Epi. Em todos os modelos foi incluído Epi e uma variável representativa do crescimento das plantas (IAF, AP, e NF), pois a utilização somente da Epi no modelo não foi suficiente para estimar ETm.

Apesar de IAF ser considerado a variável mais representativa do crescimento vegetativo das plantas - pois, teoricamente, detecta a área foliar responsável pela área transpirante - a variável fenométrica que melhor se ajustou aos dados de estimativa de ETm, juntamente com Epi, foi AP (modelo 5) (Tabela 2). Esse ajuste, geralmente menor com o IAF, em relação aos modelos que utilizam AP e NF, possivelmente está associado ao maior erro que pode ocorrer na estimativa da área foliar, pois as folhas do tomateiro são formadas por folíolos e a medida da área foliar não foi realizada em cada um dos folíolos, e sim, medido o comprimento e a largura de todo o limbo da folha. Contudo, tendo em consideração os testes dos modelos listados na tabela 2, percebe-se que a diferença entre os modelos que incluem, além de Epi, IAF (modelo 8) ou AP (modelo 5), é pequena, pois o índice c do modelo $5 \mathrm{e}$ 8 são, respectivamente, de 0,859 e 0,867 , sendo vantajosos do ponto de vista prático, visto que a medição de AP é consideravelmente mais fácil e rápida do que a de IAF.

A inclusão de variáveis meteorológicas pontuais medidas no interior da estufa $\left(\mathrm{D}_{9 ;} \mathrm{D}_{15}\right)$ nos modelos com Epi mais IAF, NF ou AP (modelos 1, 2, 3 e 4), permitiram um ajuste relativamente melhor aos dados, pois houve ligeiro acréscimo ao coeficiente de determinação e ao índice de confiança c (Tabela 2).

$\mathrm{Na}$ figura 4, está apresentada a relação entre os valores de ETm medida e a estimada pelo modelo 1, em que a variável meteorológica pontual foi $\mathrm{D}_{9}$. A dispersão, além de reforçar o bom ajuste do modelo 1 , revela a consistência desse tipo de modelo na estimativa da ETm. Entretanto, a variável déficit de pressão de vapor no ar é de mensuração mais difícil do que a temperatura do ar $\left(\mathrm{T}_{\min }\right.$ e $\left.\mathrm{T}_{15}\right)$. Assim, os modelos 6 e 9 seriam os que estimariam ETm de uma forma mais simples e prática, pois não incluem $\mathrm{D}_{9}$ nem IAF, e pelo desempenho também são considerados como ótimo $(\mathrm{O})$. Nos modelos que se utilizou IAF, apenas a introdução da variável pontual $\mathrm{D}_{9}$ proporcionou um aumento no coeficiente de determinação (modelo 4). Portanto, ao utilizar IAF juntamente com Epi, deve-se dar preferência à inclusão de $\mathrm{D}_{9}$.

Estudou-se, ainda, a influência da transformação através da raiz quadrada das variáveis fenométricas, para homogeneizar a variância (UNDERWOOD, 1981) na estimativa de ETm. Esse processo piorou o ajuste, reduzindo o $\mathrm{R}^{2}$ e o índice c, exceto para NF $\left(\mathrm{NF}^{0,5}\right)$ associado a $\mathrm{AP}$ e a Epi, verificado no modelo 10. Esse resultado parece ser apenas um acaso estatístico, visto que esse tipo de modelo foi classificado entre aqueles de pior desempenho com valores de índice de confiança c de 0,783 (Tabela 2), isto é, no limite entre os desempenhos "Bom" e "Muito bom”. Pelo contrário, Heldwein et al. (2004), trabalhando com a cultura da abóbora italiana, melhoraram 
Tabela 2. Modelos de regressão para estimativa da ETm do tomateiro cultivado em estufa plástica com os respectivos resultados e desempenho dos testes de avaliação na primavera em 2005, em Santa Maria (RS)

\begin{tabular}{|c|c|c|c|c|c|c|c|}
\hline N. ${ }^{\circ}$ & Modelos de regressão* & RMSE & $\mathbf{R}^{2}$ & $\mathbf{r}$ & d & c & Desempenho** \\
\hline 1 & $E T m=-0,85012+0,02086 A P+0,26319 E p i+0,10873 D_{9}$ & 0,3804 & 0,863 & 0,913 & 0,959 & 0,876 & 0 \\
\hline 7 & $E T m=-2,34962+0,23131 N F+0,31364 E p i+0,11902 D_{9}$ & 0,3799 & 0,860 & 0,911 & 0,958 & 0,873 & 0 \\
\hline 2 & $E T m=-0,98820+0,02179 A P+0,34540 E p i+0,02721 D_{15}$ & 0,3953 & 0,852 & 0,907 & 0,957 & 0,868 & 0 \\
\hline 4 & $E T m=-0,79007+0,79817 \mathrm{IAF}+0,29106 \mathrm{Epi}+0,15027 \mathrm{D}_{9}$ & 0,3829 & 0,850 & 0,911 & 0,959 & 0,874 & 0 \\
\hline 5 & $\mathrm{ETm}=-1,0509+0,02253 \mathrm{AP}+0,47161 \mathrm{Epi}$ & 0,3911 & 0,850 & 0,906 & 0,957 & 0,867 & 0 \\
\hline 8 & $E T m=-3,33409+0,23062 N F+0,40652 E p i+0,04757 T_{15}$ & 0,3965 & 0,847 & 0,904 & 0,955 & 0,864 & 0 \\
\hline 9 & $\mathrm{ETm}=-2,69635+0,25145 \mathrm{NF}+0,54822 \mathrm{Epi}$ & 0,3942 & 0,843 & 0,902 & 0,955 & 0,862 & 0 \\
\hline 10 & $E T m=-1,03423+0,86286 I A F+0,60053 E p i$ & 0,4000 & 0,838 & 0,900 & 0,954 & 0,859 & 0 \\
\hline 3 & $\mathrm{ETm}=-1,60628+0,01963 \mathrm{AP}+0,49020 \mathrm{Epi}+0,05209 \mathrm{~T}_{\min }$ & 0,4712 & 0,837 & 0,919 & 0,936 & 0,860 & 0 \\
\hline 6 & $\mathrm{ETm}=\mathrm{NF}^{0,5}\left(-0,15378+0,00452 \mathrm{AP}+0,07318 \mathrm{Epi}+0,0228 \mathrm{D}_{9}\right)$ & 0,3815 & 0,818 & 0,828 & 0,946 & 0,783 & MB \\
\hline
\end{tabular}

*Modelos gerados com os dados dos dias pares com todos os coeficientes angulares significativos pelo teste t a 5\% de probabilidade de erro; Epi = evaporaçáo no evaporímetro de Piche (mm); AP = altura de plantas (m); IAF = índice de área foliar; $\mathrm{NF}=$ número de folhas; $\mathrm{D}_{9}, \mathrm{D}_{15}=$ déficit de pressão do vapor no ar interno (hPa) das $9 \mathrm{~h} 00$ min e $15 \mathrm{~h}$ $00 \mathrm{~min}$, respectivamente; $\mathrm{T}_{\min }, \mathrm{T}_{15}=$ temperatura do $\operatorname{ar}\left({ }^{\circ} \mathrm{C}\right)$ mínima e das $15 \mathrm{~h}$ respectivamente.

** Desempenho conforme CAMARgo e Sentelhas (1997). RMSE: raiz do quadrado médio do erro, $\mathrm{R}^{2}$ é o coeficiente de determinaçáo da reta entre valores observados e estimados; r é o coeficiente de correlação; dé o coeficiente de Willmott e c é o índice de confiança de Camargo e SentelHas (1997).

o ajuste dos dados quando procedera a transformação dos dados. Em pimentão também cultivado em estufa plástica, ETm por unidade de IAF ao longo do ciclo foi satisfatoriamente estimada em função da evaporação medida no evaporímetro de Piche exposto à radiação solar em condiçóes semelhantes às deste trabalho $\left(\mathrm{R}^{2}=0,78\right)$ (Heldwwein et al., 2001). Porém, esta relação não se verificou para o tomateiro, pois ao se usar nos modelos de estimativa ETm por unidade de IAF $\left(\mathrm{ETm} \mathrm{IAF}^{-1}\right)$ ou sua raiz quadrada, não resultou em $R^{2}$ maiores que 0,80 . $A$ explicação pode estar relacionada com a espécie cultivada, com o hábito de crescimento, morfologia das folhas e principalmente com a época de cultivo, que no caso do tomateiro foi na primavera e na abóbora italiana e pimentão o cultivo ocorreu no outono. Nesse contexto, os modelos encontrados para ETm do tomateiro não devem ser considerados definitivos, sendo necessário verificar se estes conseguem estimar ETm da cultura em diferentes épocas do ano, com índices de confiança c semelhantes aos determinados neste trabalho.

\section{CONCLUSÃO}

É possível estimar a evapotranspiração máxima (ETm) do tomateiro com precisão aceitável para determinar a irrigação em estufa plástica, por meio de modelos que incluem a evaporação medida no evaporímetro de Piche exposto à radiação solar (Epi) e de, pelo menos, uma variável fenométrica.

A inclusão do déficit de pressão de vapor no ar medido às 9 horas $\left(\mathrm{D}_{9}\right)$ melhora a estimativa de ETm, com qualquer que seja a variável fenométrica utilizada (altura de plantas (AP), número de folhas (NF) ou índice de área foliar (IAF)).

$\mathrm{O}$ modelo $\mathrm{ETm}=-0,85012+0,02086 \mathrm{AP}+$ 0,26319 Epi $+0,10873 \mathrm{D}_{9}$ foi o que apresentou o melhor

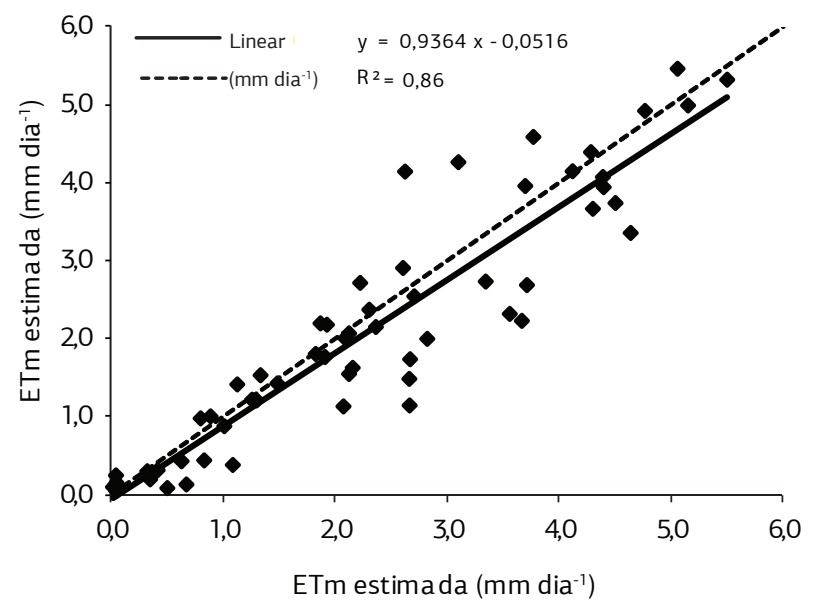

Figura 4. Regressão linear entre valores diários da evapotranspiração máxima (ETm), medidos pelo método do lisímetro de drenagem e valores da ETm estimada pelo modelo 1 para o tomateiro cultivado em estufa plástica na primavera de 2005, em Santa Maria (RS).

desempenho. $\mathrm{O}$ modelo ETm $=-1,04509+0,02253 \mathrm{AP}$ $+0,47161$ Epi pode ser considerado uma alternativa promissora para estimar a ETm do tomateiro de forma mais simples e prática nas condiçôes de ambiente protegido.

\section{REFERÊNCIAS}

BRASIL. Ministério da Agricultura. Departamento Nacional de Pesquisa Agropecuária. Divisão de Pesquisa Pedológica. Levantamento de reconhecimento dos solos do Estado do Rio Grande do Sul. Recife, 1973. 431p. (Boletim técnico, 30)

BURIOL, G.A.; ESTEFANEL, V.; SCHNEIDER, F.M.; BERLATO, M.A. Insolação e radiação solar na regiáo de Santa Maria, RS. II - Disponibilidade e Variabilidade. Ciência Rural, v.21, p.205-223, 1991. 
CAMARGO, A.P.; SENTELHAS, P.C. Avaliação do desempenho de diferentes métodos de estimativa da evapotranspiração potencial no Estado de São Paulo. Revista Brasileira de Agrometeorologia, v.5, p.89-97, 1997.

CASANOVA, M.P.; MESSING, I.; JOEL, A.; CAÑETE, A.M. Methods to estimate lettuce evapotranspiration in greenhouse conditions in the central zone of chile. Journal of Agricultural Research, v.69, p.60-70, 2009.

\section{COMISSÃO DE FERTILIDADE DO SOLO DO RIO GRANDE} DO SUL E SANTA CATARINA. Recomendação de adubação e de calagem para os Estados do Rio Grande do Sul e Santa Catarina. Passo Fundo: SBCS/EMBRAPA-CNPT, 2004. 394p.

DALMAGO, G.A.; HELDWEIN, A.B.; NIED, A.H.; GRIMM, E.L.; PIVETTA, C.R. Evapotranspiração máxima da cultura de pimentão em estufa plástica em função da radiação solar, da temperatura, da umidade relativa e do déficit de saturaçáo do ar. Ciência Rural, v.36, p.785-792, 2006.

DOMUTA, C.; CARBUNARU, M.; MARIA, S.; BANDICI, G.; SABAU, N.C.; ALINA, S.; ALINA, S.; IOANA, B.; DOMUTA, C. Use of the piche evaporimeter in the irrigation scheduling of the tomatoes in the conditions from the solarium. Protectia Mediului, v.12, p.40-45, 2007.

ELINGS, A.; VOOGT, W. Management of greenhouse crop transpiration: the way forward. Acta Horticulturae, n.80, p.12211228, 2008.

EMPRESA BRASILEIRA DE PESQUISA AGROPECUÁRIA EMBRAPA/CNPS. Sistema brasileiro de classificação de solos. Rio de Janeiro, 2006. 306p.

ESTEFANEL, V.; BURIOL, G.A.; ANDRIOLO, J.L.; LIMA, C.P.; LUZZI, N. Disponibilidade de radiação solar nos meses de inverno para o cultivo do tomateiro (Lycopersicun esculentum Mill.) na região de Santa Maria, RS. Ciência Rural, v.28, p.553-559, 1998.

FARIAS, J.R.B.; BERGAMASCHI, H.; MARTINS, S.R. Evapotranspiração no interior de estufas plásticas. Revista Brasileira de Agrometeorologia, v.2, p.17-22, 1994.

GONZALEZ-SANPEDRO, M.C.; LE TOAN, T.; MORENO, J.; KERGOAT, L.; RUBIO, E. Seasonal variations of leaf area index of agricultural fields retrieved from Landsat data. Remote Sensing of Environment, v.112, p.810-824, 2008.

HELDWEIN, A.B.; DALMAGO, G.A.; STRECK, L.; TAZZO, I.F.; TRENTIN, G. Utilização do evaporímetro de Piche exposto à radiação solar para estimar a evapotranspiração máxima do pimentão em estufa plástica. Revista Brasileira de Agrometeorologia, v.9, p.213-217, 2001.

HELDWEIN, A.B.; STRECK, L.; SCHNEIDER, F.M.; GRIMM, E.L.; NIED, A.H.; TAZZO, I.F. Modelos para a estimativa da evapotranspiração máxima da abóbora italiana em estufa plástica. Revista Brasileira de Agrometeorologia, v.12, p.75-86, 2004.
MANRIQUE, L.A. Greenhouse crops: a reviews. Journal of Plant Nutrition, v.16, p.2411-2477, 1993.

MARTINS, S.R.; FERNANDES, H.S.; ASSIS, F.N. de; MENDEZ, M.E.G. Caracterização climática e manejo de ambientes protegidos: a experiência brasileira. Informe Agropecuário, v.20, p.15-23, 1999

MORENO, J.A. Clima do Rio Grande do Sul. Porto Alegre: Secretaria da Agricultura, 1961. 46p.

ORGAZ,F.;FERNÁDEZ,M.D.; BONACHELA,S.;GALLARDO, M.; FERERES, E. Evapotranspiration of horticultural crops in an unheated plastic greenhouse. Agricultural Water Management, v.72, p.81-96, 2005.

ORTEGA-FARÍAS, S.; CALDERON, R.; MARTELLI, N.; ANTONIOLETTI, R. Evaluacion de un modelo para estimar la radiacion neta sobre un cultivo de tomate industrial. Agricultura Técnica, v.61, p.41-49, 2004.

PAPAIOANNOU, G.; KALOUDIS, S.; KERKIDES, P. On the proper employment of Piche evaporimeters in estimating evapotranspiration. International Journal of Climatology, v.18, p.1247-1260, 1998.

REZENDE, F.C.; ALVES, D.R.B.; FURLAN, R.A.; PASSOS, K.S.; FRIZZONE, J.A.; FOLEGATTI, M.V. Determinação da evaporação em casa de vegetaçấo utilizando tanque reduzido e atmômetro. Irriga, v.9, p.282-288, 2004.

SAS Institute INC. The SAS-system for Windows: release 6.12 (software). Cary: Statistical Analysis System Institute, 1997. $1167 \mathrm{p}$.

UNDERWOOD, A.J. Techniques of analysis of variance in experimental marine biology and ecology. Oceanography and Marine Biology Annual Review, v.19, p.513-605, 1981.

VALANDRO, J.; ANDRIOLO, L.G.; BURIOL, G.A. Dispositivo lisimétrico simples para determinar a transpiração das hortaliças cultivadas fora do solo. Revista Brasileira de Agrometeorologia, v.7, p.189-193, 1999.

WILLMOTT, C.J. Some comments on the evaluation of model performance. American Meteorological Society, v.3, p.1309-1313, 1985.

XAVIER, A.C.; VETTORAZZI, C.A. Leaf area index of ground covers in a subtropical watershed. Scientia Agricola, v.60, p.425$431,2003$.

ZHANG, Z.-K.; LIU, S.-Q.; LIU, S.-H.; HUANG, Z.-J. Estimation of Cucumber Evapotranspiration in Solar Greenhouse in Northeast China. Agricultural Sciences in China, v.9, p.512$518,2010$. 